\title{
Adatable Industrial 4.0: An Improvement Detected Obsolete Bushing Condition on Rubber Curing Machine Industry
}

\author{
Agus Purwanto \\ Department of Mechanical Engineering \\ Swiss German University \\ Tangerang 15143, Indonesia \\ Email: agoezpoer@gmail.com
}

\author{
Edi Sofyan \\ Department of Mechanical Engineering \\ Swiss German University \\ Tangerang 15143, Indonesia
}

\begin{abstract}
Bushing is a part of rubber curing machine that have function as cushion pin joint, generally make from a bronze material. Pin joint have a function to connected with 1 paired linkage arm with rotated crank gear of each via pin joint to get closing force at rubber curing machine when mould closed. When bushing condition at pin joint on rubber curing machine was not good caused by friction. It will make closing force linkage arm left and right (1 pair) on rubber curing machine unbalanced. So it will make closing force to force closed rubber mould undistributed evenly, so it caused mould rubber closed with gap. This condition will make defect rubber product open mould after cured finished. In this case is important to find new method detection and monitored bushing condition. This research was done by measured vibration around pin joint at linkage arm by taking data of sound and acceleration on the real object research and used 2D software simulator to measured bushing condition good or not. Acceleration measurement was done by measured at axis $Y$ and $Z$ by used accelerometer sensor, and accelero sensor on cell phone via sains journal android application. And collected the data stress value on linkage arm by used needle dial gauge millimetre scale. By simulation software are measured acceleration at axis $X$ and $Y$ with good bushing condition or vise versa. The actual data that was collected: acceleration, sound vibration and stress value and simulated data by software to be compare the amplitude and choose the biggest amplitude as new method measurement of vibration to detect and monitor bushing condition. From the result data, detection of vibration around pin joint by acceleration value by used accelerometer sensor measured at axis $\mathrm{Y}$ and $\mathrm{Z}$ more prefer with the other measurement method.
\end{abstract}

Keywords: Vibration, predictive maintenance, accelerometer, sounds sensor level.

\section{INTRODUCTION}

In rubber manufacturing industry, especially for rubber curing machine with arm type have many bushing on two position where pin joint created there are driving shaft bushing left and right side [7], where bushing have function as cushions rotating pin joint joint arm. Its very important to be monitored bushing condition because every changing obsolete bushing will be changing closing force of rubber curing machine.

A two position of measurement of vibration on measurement system with bandwith $500 \mathrm{~Hz}$ can be build with low price component by using MPU6050 micro electrical mechanical system (MEMS) [8].

Vibration analysis can be involved mobile devices or other experiments such as system identification and structural monitoring using a self develop application that called is Dynamic. It can be analysed different between professional accelerometer and sensor accelero on smartphone. Finally application limited by corresponding smartphone feature [1].

The hypothesis is shown in Figure 1. In order how to maintain obsolete bushing condition on rubber curing machine we focused find out new metode to detection and monitored obsolete level of bushing on rubber curing machine with arm type.

\section{Methodology}

There are many question about adaptable industrial 4.0 era, especially to find out new metode for control and detect healthy level every machine in industrial line production. In this case is important how to monitoring and detecting each part of rubber curing machine arm type with many bushing every joint. This is another metode to check and control healthy level every machine mainly obsolete level bushing on rubber curng machine on isndustrial rubber company.

Therefore the study the study is conducted with the scope of the following :

1) Experiment on rubber curing machine directly. As mentioned in the early chapter of the questions related to the detection of vibration nearly on pin joint arm on rubber curing machine, to sense and detected obsolete level of bushing at pin joint. In this research we put one machine curing model as the object of research.

2) Record data. By recorded the data on machine model by many sensing to get many data. We used accelero sensor, journal android application on smartphone to sensing and record by sound level sensor and accelerometer on smartphone.

3) Modeling and simulated. By used 2D software modelling it can be drawn replica of the rubber curing machine model, and it can be simulated and recorded 


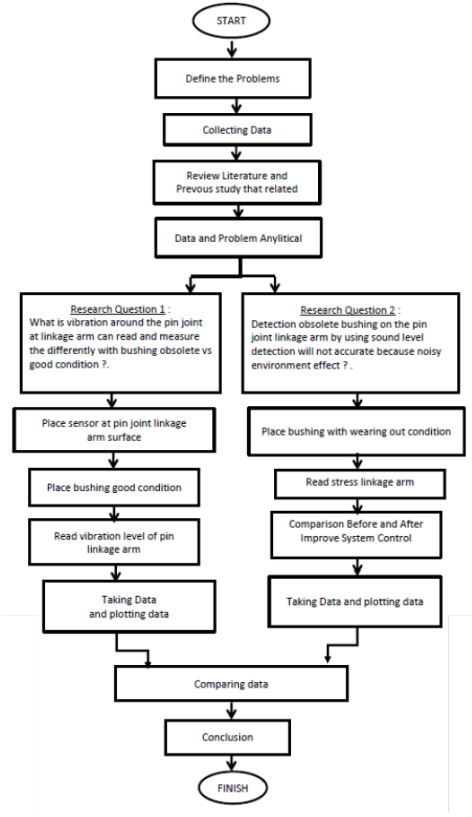

Fig. 1. General Research Method.

at place that we want to measure and recorded. In this case we measure vibration at around pin joint linkage arm on rubber curing machine. From the recorded data it can be plotted become graph of vibration with $\mathrm{X}$ axis and $\mathrm{Y}$ axis measurement.

\section{RELATED WORKS}

\section{A. Current research in vibration sensing and sound sensing}

Vibration on the soil it can be measured by used accelerometer that have been mounted in different condition mounting bases anchored. Three type anchored are one anchored, three anchored and four anchored. After that vibration generated by used Light Falling Weight Deflectometer (LFWD) and recorded vibration level in longitudinal, transversal and vertical direction with various distances from 5 until 10 meter from the source of vibration. Measured vibration level used accellero sensor type TLD356B18 manufactured by PCB Piezotronics [5].

Desain to improved the anti-vibration performance of vortex flow meter by signal effect from interference directional noise. At this condition is needed to desain new probe structure based on three axis accelerometer. Data from accelerometer used to analyze and optimize the material by check the harmonic response for improved shape desain of probe tip [3].
Measuring freuquency downhole hydraulic impact by using an acoustic sensor and accelerometer sensor. Vibration data get from 2 input sensor, firstly detection by sound level and secondly acceleration sensing data. From experiment result by used accelerometer method and the non-treshold decicibel sensor method are more accurate than experiment by used threshold acoustic sensor when measured working downhole [2].

Vibration level it can be measured and recorded to analyze system identification and structural manufacturing. By used application on mobile device and sensor existing on mobile phone can be done [1].

By sampling data it can be show percentage the habbit user when maximized facility on smartphone $94 \%$ of sample population used 3 axis accelerometer, $89 \%$ used e compass, and $71 \%$ used gyroscope [6].

Working Model 2D is a software that can be used to desain and simulated on 2 dimension shapes. By simulated 2D model replica with movement, measuring and recorded can be done at the same time used this software [4].

\section{DESAIN OF EXPERIMENT}



Fig. 2. The experiment desain configuration (a) One side linkage arm Rubber curing machine. (b) Zooming placement position accelerometer sensor and smartphone recorded vibration at pin joint.

We can see in Figure 2(a), it is just one side rubber curing machine where pin joint and linkage arm rubber curing machine and shaft bushing placed. In this experiment just only used one machine at one side for taking data vibration. Previuosly before experiment done, analysis obsolete level of shaft bushing only by visual check value of stress force that have pointed by nidle dial gauge with milimeter scale. When mould at closed condition linkage arm will get stress force effect linkage arm pull upper mould closed with lower mould with certain closing force. In Figure 2(b), it is the zooming accelerometer sensor that have been connected with board microprocessor that was connected with PC for recorded data and smartphone for comparing data acceleration. 

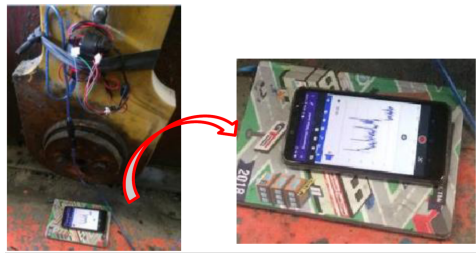

(a)

(b)

Fig. 3. (a) Placement position accelerometer sensor and sound level sensor via smartphone recorded vibration at pin joint. (b) Zooming placement position accelerometer sensor and sound level sensor via smartphone recorded vibration at pin joint.

\section{A. Existing condition measurement stress force to monitored} bushing level condition.

Previously, detected bushing level condition just only prediction by visual check value that have been pointed by needle dial gauge when rubber curing machine closed condition (Fig.4).

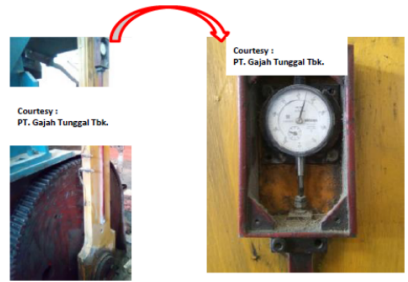

Fig. 4. Placement nidle dial gauge milimeter scale at pin joint and zooming needle dial gauge

\section{Result AND ANALysis}

The result analysis will be incorporated the two source of studies (experiment and collected by recorded data experiment) in draft analysis that have been discussion before :

\section{A. Actual data recorded from experiment on rubber curing} machine.

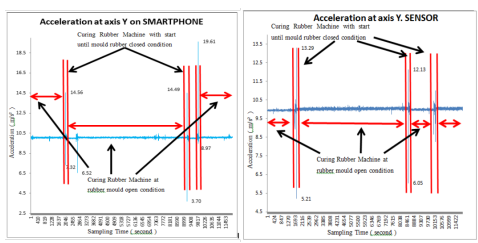

Fig. 5. Vibration data from accelerometer sensor and smartphone sensor on Y-axis movement detection.

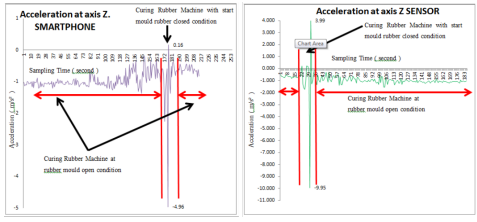

Fig. 6. Vibration data from accelerometer sensor and smartphone sensor on $\mathrm{Z}$-axis movement detection.

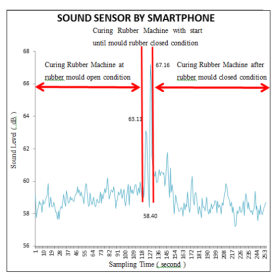

Fig. 7. Vibration data from sound sensor to detect the decibel level.

B. Actual data by simulated with $2 D$ Software comparing vibration pin joint with obsolete and good bushing condition.

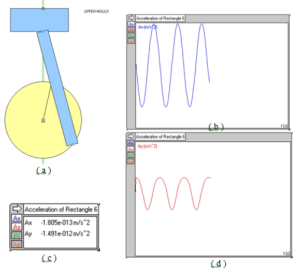

Fig. 8. Good bushing condition vibration simulted by using 2D simulation software by measured axis $\mathrm{X}$ and $\mathrm{Y}$.



Fig. 9. Obsolete bushing condition vibration simulted by using 2D simulation software by measured axis $\mathrm{X}$ and $\mathrm{Y}$.

Existing measurement on linkage arm rubber curing machine by using nidle dial gauge to measure bushing condition. 
(Data - 1)



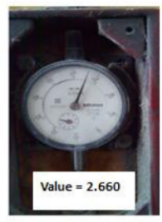

(Data - 2)

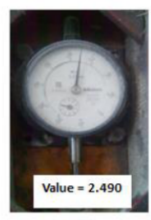

(Data - 3)
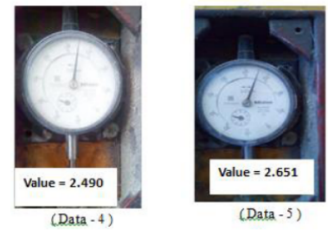

Fig. 10. Value stress force on linkage arm by used nidle dial gauge milimeter scale.



Fig. 11. Graph value stress force on linkage arm by used nidle dial gauge milimeter scale.

\section{CONCLUSION}

From the analytical data that have been collected after measurement using 5 methods :

1) Measure and record vibration point at the $Y$ axis by accelerometer and accelero sensor on android smartphone via jurnal sains android application.

2) Measure and record vibration level at the $Z$ axis by accelerometer and accelero sensor on scmartphone via jurnal sains android application.

3) Measure and record vibration by sound level sensor on android smartphone via jurnal sains android application.

4) Measure and record vibration by simulation on Working Model 2D Software with obsolete bushing at pin joint with abnormal condition.

5) Measure displacement linkage arm by visual check pointed niddle dial gauge by measure displacement.

From the 5 methods measured of vibration around pin joint at linkage arm on rubber curing machine, it could be conclused that (i) vibration level measurement more accurated using $\mathrm{Y}$ and $\mathrm{Z}$ axis that was read by accelero, because the measurement value have similar pattern when simulated with working model $2 \mathrm{D}$, (ii) vibration level by measuring sound level vibration not accurate, because are have more distortion from the other machine activity or the process that done around the sensor level, (iii) 2D working model software can be simulated worn out and good bushing at pin joint linkage arm, (iv) displacement measurement by visual check that have been pointed by nidle dial gauge look are similar although bushing condition was worn out, and (v) by Adding Control Chart Upper and Lower Control Limit using XmR Chart it can be monitored time for changing bushing with the new one if peak data acceleration go out from the line control.

So, this research for measuring vibration level to analytical worn out bushing on the pin joint linkage arms are preffered using measured vibration level on axis $\mathrm{Y}$ and $\mathrm{Z}$ around pin joint on linkage arm at Rubber Curing Machine used accelerometer. By adding Control Chart XmR Chart, acceleraton data around pin joint it can be be monitored and knowing the time for changing bushing with the new one. If the acceleration peak data go out from the Upper and Lower Control Limit it is mean that time for changing of bushing at pin joint on rubber curing machine with the new one.

\section{RECOMMENDATIONS}

The signal analog coming from detected on the axis $\mathrm{Y}$ and $\mathrm{Z}$ accelero by measured vibration can be combine the $\mathrm{CNN}$ to help an engineer to get new methods for detection earlier to fixed time for replacing bushing to support Predictive Maintenance. So, Predictive Maintenance more accurate when applied this new methods. And the next research for measured and reading vibration cam be monitored real time and give output signal warning to inform the mechanical engineer by acces data cloud, so industrial 4.0 era can be done especially to maintain bushing machine.

\section{REFERENCES}

[1] A. Feldbusch, H. S.-A. P. A., Vibration analysis using mobile devices (smartphones or tablets). Procedia Engineering, 199 http://www. sciencedirect.com/science/article/pii/S1877705817340614, p. 2790. 2017

[2] Chuan Wu, G.-j. W. X.-m. W. W.-q. W. L. H. F. Z., Using an acoustic sensor and accelerometer to measure the downhole impact frequency of a hydraulic impactor,. Journal of Natural Gas Science and Engineering,, 27, part 3 http://www.sciencedirect.com/science/article/pii/ S1875510015301608, p. 1296. 2015

[3] Hongjun Sun, F. G. T. Y. Z. L., Anti-vibration analysis of vortex probe based on three-axis acceleration measurement,. Flow Measurement and Instrumentation, $58 \mathrm{http} / / / \mathrm{www} . \mathrm{sciencedirect.com/science/article/pii/}$ S0955598616301273, p. 21. 2017

[4] Knowledge Revolution, Working Model 2D. Version 4.0 ed. San Mateo, California: USA. 1996

[5] Krzysztof Robert Czech, W. G., Measurement of Surface Vibration Accelerations Propagated in the Environment. Procedia Engineering,,189 http://www.sciencedirect.com/science/article/pii/S187770581732129X, p. 45. 2017

[6] Martin, J., Internet of things designline. Connectivity \& Sensor : Smartphone Essentials, 17 November, p. 2. 2018

[7] Seyen Machinery Co., Ltd, Mesin Tube Curing Press Am Tube Operating Instructions. 1 ed. Taiwan: Seyen Machinery. 2006

[8] Yum Ji Chan, J.-W. H., Multiple-point vibration testing with micro-electromechanical accelerometers and micro-controller unit. Mechatronics, 44 http://www.sciencedirect.com/science/article/pii/ S0957415817300545, p. 84. 2017 